\title{
MOTONEURON DEATH AND MOTOR UNIT SIZE DURING EMBRYONIC DEVELOPMENT OF THE RAT ${ }^{1}$
}

\author{
A. J. HARRIS ${ }^{2}$ AND C. D. McCAIG
}

\author{
Department of Physiology, University of Otago, Dunedin, New Zealand
}

Received December 3, 1982; Revised June 27, 1983; Accepted June 27, 1983

\begin{abstract}
Chronic paralysis of rat embryos during the last 4 to 6 prenatal days causes a diminution in skeletal muscle fiber numbers but inhibits motoneuron death. Consequently, as paralyzed muscles develop, an increased number of motoneurons attempts to form synapses at a reduced number of synaptic sites. Paralyzed muscle fibers receive their synapses at a single endplate, as in control muscles, but these endplates are hyperinnervated, with about twice the normal number of inputs. Counts of axons, synaptic inputs, and muscle units showed that motoneurons normally contact a maximum number of muscle fibers shortly before birth, and this number remains stable for several days postnatal until it finally is reduced to the adult number.

The average motor unit size in paralyzed embryos at the time of birth was the same as in controls. We suggest that it is not necessary to postulate the existence of competition between embryonic nerve terminals in order to explain regulation of the number of muscle fibers initially contacted by a motoneuron.

Motoneuron death was not immediately affected by paralysis, but paralysis "rescued" all motoneurons whose death normally would have occurred $24 \mathrm{hr}$ or more after the time when paralysis was initiated, regardless of when this was. This implies that the peak period for determination to die is during embryonic day 14, when myotube formation is just beginning and no recognizable endplate structures are present in muscles. When paralyzed, motoneurons normally destined to die are capable of forming a normal number of functional nerve-muscle contacts.
\end{abstract}

The development of the nervous system depends to a remarkable extent upon the execution of instructions laid down in individual cells at the time of their formation. As pointed out by Stent (1981), the genome does not contain a "program" for the nervous system in the sense in which an engineer possesses a circuil diagram for the construction of a computer. Accordingly, once the stage is set for the brain to develop, neurons acting in this drama must rely upon memorization of their roles, and cannot check their performances against a script. Development does not, however, take place totally without prompting or feedback. There are, for example, "critical periods" when synaptic function may be permanently modulated in response to external inputs (Hubel and Weisel, 1970). At earlier times, inductive or competitive interactions between groups of cells may stimulate tissue growth or cause synaptic withdrawal or cell death.

Accordingly, when studying neural development, it is

\footnotetext{
${ }^{1}$ We thank Peter Ashworth for expert technical help and Noel Still for illustrations. This work was supported by the New Zealand Medical Research Council.

2 To whom correspondence should be addressed.
}

of interest to distinguish between features which are invariant and those which may be modulated as a result of cell or tissue interactions or in response to external inputs. The experiments described here concern the interactions between spinal motoneurons and skeletal muscle. The development of each of these tissues depends on the other: motoneurons deprived of access to muscle die (Romanes, 1946; Oppenheim et al., 1978), and, in turn, muscle development depends critically on both the presence and the function of its innervation (Harris, 1981a). These bulk interactions result in a very precise pattern of muscle innervation and an accurately determined number of muscle fibers within the muscle (Luff and Goldspink, 1970; Hooper, 1978).

In our experiment, excessive numbers of motoneurons attempt to form synaptic connections with a diminished number of muscle fibers. Embryonic rat diaphragm muscle fiber numbers were reduced by chronic paralysis during the last 4 to 6 days before birth (Harris, 1981a). Paralysis of avian embryos causes an increase in motoneuron numbers (Laing and Prestige, 1978; Pittman and Oppenheim, 1978; Creazzo and Sohal, 1979), and we show here that the same is true in the rat. Consequently, as 
paralyzed muscles develop, an increased number of motoneurons attempts to form synapses at a reduced number of synaptic sites. By counting the number of synaptic inputs to each muscle fiber, we were able, knowing the numbers of muscle fibers and motoneurons supplying the muscles, to estimate the number of muscle fibers contacted by each motoneuron, both in control embryos and after paralysis can be presumed to have abolished any competitive mechanisms. In comparing these results, we ask whether regulation of embryonic motor unit size (before the postnatal episode of terminal elimination) depends on competition between terminals or on a mechanism intrinsic to individual motoneurons.

Apart from the recent description of constancy of motor unit size in the developing chick posterior latissimus dorsi (PLD) muscle by Bourgeois and Toutant (1982), previous work on this topic is confined to neonatal animals. Brown et al. (1976), in a study of the soleus muscle, found that motor unit size was not increased by partial denervation and suggested that there is an intrinsically determined upper limit to the number of muscle fibers contacted by each motoneuron. Furthermore, motor units in partly denervated muscles were reduced in size during the final stage of retraction of polyneuronal innervation, even though this appeared to result in the complete denervation of some muscle fibers. Their evidence for denervation is indirect and, if true, has the important implication that postnatal reduction of motor unit size cannot be fully accounted for by competition between contiguous synaptic terminals. Their conclusions on retraction have been questioned by Betz et al. (1980), who, in a different muscle with a different mix of muscle fiber types, give evidence that in the absence of competition, motor unit size is not reduced.

Another aspect of development of neuromuscular junctions is illustrated in the elegant experiments of LanceJones and Landmesser (1981). Several spinal cord segments destined to contain motoneurons projecting to hindlimb muscles were removed from early chick embryos. Subsequently, hindlimb muscles normally destined to be innervated by the missing segments formed, but were never innervated. Motoneurons left intact projected only to their appropriate targets, and the authors conclude that competition can be excluded from any major role in the development of specific motoneuron connections in the chick hindlimb. Iamb (1981) has arrived at a similar conclusion from experiments on development of innervation in amphibian limbs.

There are many instances during development when axons, in greater numbers than will be present at maturity, converge onto a potential target. The eventual development of an orderly pattern of synaptic contacts is usually described figuratively as "competition." The power of this metaphor is such that it often is assumed to describe mechanism. Competition as a mechanism underlying the formation of nerve-muscle junctions should be understood to mean that survival of a particular terminal depends on whether or not other connections are present. The explanatory power of this term is such that we suggest it should be used only when there is clear experimental evidence of this kind.
Our experiments give an estimate of the size of motor units in embryonic muscles up to a stage when about one-half of the adult number of muscle fibers has formed, before the period of elimination of multiple synaptic inputs which begins shortly after birth in the rat (Redfern, 1970; Brown et al., 1976; Betz et al., 1979, 1980). We suggest that the number of muscle fibers initially contacted by a motoneuron is invariant and not modulated by competition for synaptic sites. This property of motoneurons may serve to ensure formation of an adequate number of motor units in a mature muscle.

\section{Materials and Methods}

Paralysis of embryos. Embryos were paralyzed with glass capillaries containing tetrodotoxin (TTX) purchased from Sankyo (Mills and Bray, 1979; Harris, 1981a). We now find that paralysis can be maintained by a capillary placed inside the amnion without being inserted into the embryo. This improvement in technique, combined with careful control of the size of the pore, makes it possible reliably to paralyze embryos from E15 (embryonic day 15; the day a copulatory plug was present at 9:00 A.M. is E0) until E21 with a single capillary. Most experiments described here were done with embryos paralyzed during the interval E16 or E17 to E21, so that results could be correlated with data for muscle fiber numbers obtained from an earlier series of experimental animals (Harris, 1981a, b). Pregnant does can tolerate a maximum of four capillary implants, and, as only one embryo was required for physiological experiments, we usually paralyzed two or three, enough to allow for accidents in dissection or mounting. The criteria for paralysis were complete flaccidity and an absence of reflex body flexion in response to strong ( $100 \mathrm{~V}$ $\times 0.5 \mathrm{msec}$ at $10 \mathrm{~Hz}$ ) electrical stimulation of the snout. The operative procedures are relatively nontraumatic, and we normally expect all treated embryos to survive.

Intracellular recording. All records were made from the left hemidiaphragm of E21 embryos. The muscle was mounted in an organ bath perfused with an oxygenated saline solution containing $150 \mathrm{mM} \mathrm{NaCl}, 5 \mathrm{mM} \mathrm{KCl}, 4$ $\mathrm{mM} \mathrm{CaCl}_{2}, 4 \mathrm{mM}$ HEPES buffer, adjusted to $\mathrm{pH} \mathrm{7.2,} 0.02$ mM choline, and 1\% serum (horse or calf). Muscle twitching in response to nerve stimulation was abolished by addition of $d$-tubocurarine (dTC; Sigma). Concentrations required for paralysis ranged from $5 \mu \mathrm{M}$ for control tissues up to $100 \mu \mathrm{M}$ for tissues from TTX-treated animals. As can be seen from these figures, embryonic muscles were insensitive to this drug, which also has a powerful depolarizing action (Ziskind and Dennis, 1978). Many other drugs were tried in an unsuccessful attempt to find a better one. Muscles from paralyzed embryos fibrillated vigorously until the addition of dTC caused them to become depolarized.

Intracellular recording employed conventional microelectrode techniques. Resting potentials were continuously monitored on a pen recorder, and endplate potentials (epps) were displayed on an oscilloscope. The criterion for a successful impalement was that it should give rise to a resting potential of at least $50 \mathrm{mV}$ (control muscles) or $45 \mathrm{mV}$ (paralyzed muscles) that was maintained for the duration of the analysis. It was not possible 
to apply the $50 \mathrm{mV}$ criterion to fibers from paralyzed muscles as the high concentration of dTC required for paralysis depolarized the majority to this level or below. In dTC-free bathing medium, good penetrations of both control and paralyzed muscles gave resting potentials in excess of $70 \mathrm{mV}$ (Dennis et al., 1981).

The phrenic nerve was dissected back to the neck before removing the diaphragm from the embryo, and the end of the nerve segment was held in a suction electrode. High intensities of cathodal stimulation often gave rise to the sudden appearance of additional epps with a reduced latency, apparently as the result of action potentials initiated closer to the muscle so that two action potentials were generated in each axon. This artifact was avoided by making the external lead on the suction electrode the anode.

In control muscles, the number of synaptic inputs to a fiber was estimated by counting increments in epp amplitude as the intensity of nerve stimulation was increased (Redfern, 1970; Dennis et al., 1981). In paralyzed muscles we took advantage of the fact that epps showed rapid accommodation, allowing us to see increments in response against a stable background. The intensity of nerve stimulation was slowly increased until an increment in response was seen. Stimulation was then maintained at this level, at 0.5 or $1 \mathrm{~Hz}$, until the response had declined to a steady level. The stimulus intensity was again increased until a new increment was seen, and the procedure was repeated. When a maximum level of response had been reached, the stimulus intensity was slowly decreased and the number of decrements in the response was noted. This procedure was repeated three times for each endplate, and the number of synaptic inputs was taken as the mean of the three records. Although more sensitive, this procedure is not different in principle from that applied to control muscles where accommodation is less marked. Accommodation was sufficiently rapid that less than half a dozen stimulatory pulses of constant intensity usually sufficed to produce a stable level of response. Successive trials usually gave the same value, and a difference greater than one indicated a change in the quality of the penetration.

Histology. Embryos were perfused through the heart with ice-cold fixative ( $1 \%$ paraformaldehyde, $1.25 \%$ glutaraldehyde, $20 \mathrm{mM}$ HEPES buffer adjusted to $\mathrm{pH} 7.2$, $120 \mathrm{mM} \mathrm{NaCl}, 5 \mathrm{mM} \mathrm{CaCl} 2$ ). Tissues were then dissected and placed in fixative for a total of 30 to $60 \mathrm{~min}$ fixation before washing in buffer and preparation for light or electron microscopy.

Motoneuron counts were made from pieces of thoracic spinal cord. A length of cord running from the T1 nerve roots to the $\mathrm{T} 6$ nerve roots was freed from the spinal cord and embedded in paraffin. A complete set of $12-\mu \mathrm{m}$ sections was collected and stained with thionin. The number of motoneurons in every fifth section was counted using a $\times 40$ objective.

Phrenic nerves and C5 dorsal and ventral roots were dissected from the same embryos and were examined with electron microscopy. Tissues were postfixed with osmium, dehydrated in alcohol, and embedded in Agar100 resin. Phrenic axon counts were made from sections cut transversely near either end of a length of nerve running from the point of entry into the thorax to near where it bifurcates before entering the diaphragm. Dorsal and ventral root axon counts were made from transverse sections of the $\mathrm{C} 5$ roots in the mid to distal region. Sections were mounted on Formvar films, stained with uranyl acetate-lead citrate, and examined in a Phillips 300 electron microscope. Photomontages were prepared at final magnifications ranging from $\times 5,570$ to $\times 11,700$, as appropriate to the developmental stage of the tissue.

Axons and Schwann cell nuclei were counted manually and marked to avoid double counting. Phrenic nerve axons were classified into two groups. The first was comprised of axons destined to become myelinated. These were identified as profiles individually wrapped by Schwann cell cytoplasm (Fig. 3). The second group comprised small-diameter axons $(0.1$ to $0.4 \mu \mathrm{m})$ grouped together as a bundle within a single Schwann sheath. No distinctions were made when counting ventral root axons.

Phrenic nerve diameters were estimated as the mean of four diameters rotated at $45^{\circ}$ angles to one another. A mean diameter for ventral root axons was estimated by measuring the diameters of axons in three nerve fascicles: the first fascicle contained the largest axon in the root, the second was a randomly chosen peripheral fascicle, and the third was a central fascicle. The proportion of axons measured in each root ranged from 5 to $9 \%$ (77 to 113) of the total.

In order to see whether changes in the number of axons in a nerve were accompanied by changes in the number of Schwann cells, the number of Schwann cell nuclei per complete transverse section was counted from photomontages of phrenic nerves and ventral roots. The ratio of axons to Schwann cell nuclei was then calculated. If the number of Schwann nuclei per section bears a constant relation to the number of Schwann cells in the nerve in both experimental and control animals, then this ratio relates the number of axons in the nerve to a fixed (but unknown) proportion of the total number of Schwann cells.

\section{Results}

\section{Time course of motoneuron death}

The time course of motoneuron death was assessed by counting the number of C5 ventral root fibers in embryos of various ages (Fig. 1). The greatest loss of axons occurred between E15 and E16, with numbers falling from 6900 to 2400 ; there was a futher slow reduction to 1200 at E21. Ninety-five percent of the loss had taken place by E18. We did not attempt to count motoneuron cell bodies other than in E21 embryos where they could be identified by their prominent Nissl substance.

\section{Effect of paralysis on motoneuron numbers}

Numbers of motoneurons in paralyzed embryos were estimated in three ways: by counting $\mathrm{C} 5$ ventral root axons, counting phrenic nerve axons, and counting motoneuron cell bodies in spinal segments $\mathrm{T} 1$ to $\mathrm{T} 6$, all at E21.

Thoracic motoneurons. Sections of spinal cord from embryos paralyzed during E16 to E21 were distinctly 


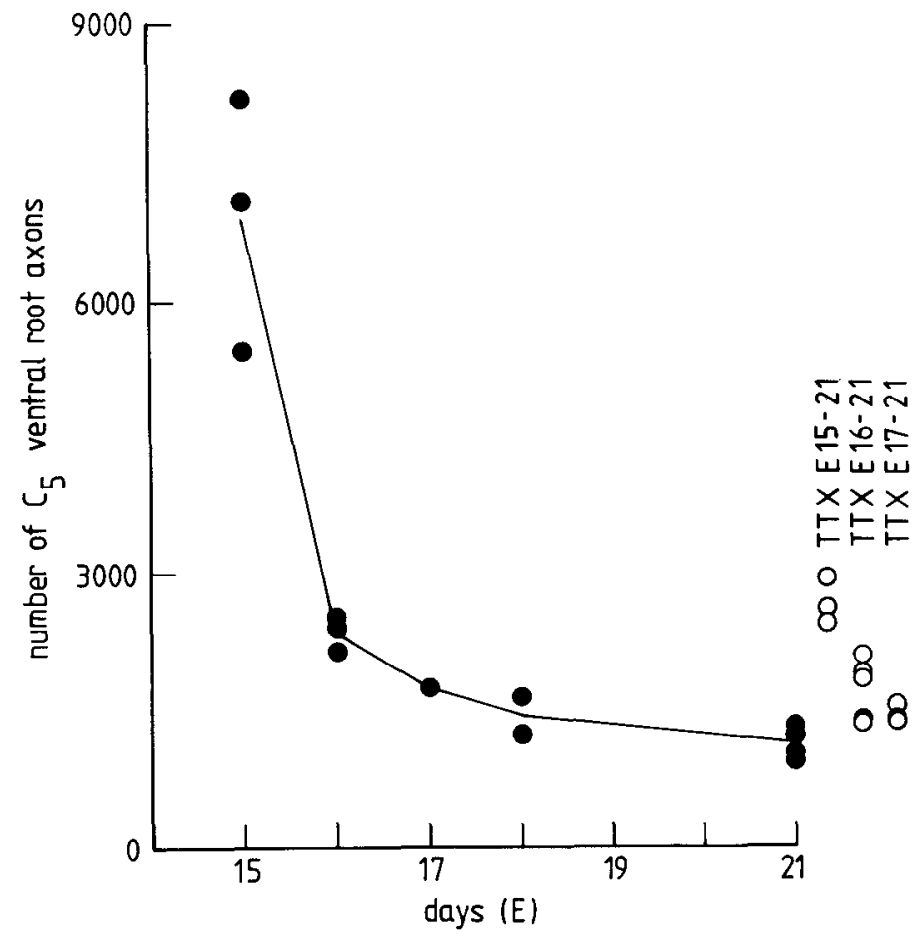

Figure 1. Numbers of C5 ventral root axons in rat embryos aged E15 to E21 (solid circles) and numbers of axons in E21 embryos that were paralyzed during the intervals listed (open circles).

different from controls. Motoneurons formed a compact column in the ventral horn, in contrast to control cords in which the principal aggregation was more diffuse, with motoneurons scattered dorsally above it (Fig. 2). The six rostral thoracic segments of paralyzed cords contained $130 \%$ of the number of motoneurons in control cords (Table I).

Phrenic nerve axons. Premyelinated axons (Fig. 3) were identified as described under "Materials and Methods." E21 embryos paralyzed from E15 possessed 216\% of the number in E21 controls, and embryos paralyzed from E16 possessed 157\% (Table I). The increased axon numbers were paralleled by a proportionate increase in the number of Schwann cell nuclei (Fig. 4). Paralyzed nerves showed a slight increase in diameter (E21 controls, $66 \mu \mathrm{m}$; paralyzed E16 to E21, $73 \mu \mathrm{m}$ ). There was no difference in the number of premyelinated axons between proximal and distal ends of the nerves, whether control or paralyzed. Small-diameter axons running in Remak bundles were, by contrast, twice as numerous in proximal sections of the nerve as in sections made close to the diaphragm (Table I). Their numbers were not affected by paralysis. In addition, paralysis did not lead to an increase in the number of autonomic axons accompanying the external intercostal blood vessel (Harris and McCaig, 1983).

C5 spinal root axons. Dorsal and ventral root axons were counted in control embryos of various ages up to E21, and in paralyzed embryos at E21 (Figs. 1 and 5). All axons were counted, as even at E21 it was not always possible to distinguish premyelinated axons in dorsal roots. Ventral root axons showed their greatest incidence of loss between E15 and E16, with $66 \%$ of the axons present on E15 disappearing within $24 \mathrm{hr}$; these accounted for $79 \%$ of the fibers due to disappear between E15 and E21. At E21, embryos paralyzed since E15 had $229 \%$ of the number of axons in E21 controls, embryos paralyzed since E16 had 147\%, and embryos paralyzed since E17 had $124 \%$.

Maximal loss of dorsal root axons occurred at about the same time as that of motor axons, between E15 and E16 (Fig. 5). We did not make counts earlier than E15. Dorsal root axons were not saved from cell death by paralysis during E15 to E21 or E16 to E21, the numbers of axons in paralyzed embryos being $96 \%$ and $90 \%$, respectively, of those in E21 controls (Fig. 5).

As in phrenic nerves, the ratio of axons to Schwann cell nuclei in paralyzed roots was not significantly different from that in E21 controls (with a possible slight reduction in relative number of Schwann cells in roots from embryos paralyzed during E15 to E21; Fig. 4). These results indicate that Schwann cell numbers are determined by the number of axons and are not affected by paralysis.

The mean diameter of ventral root axons was reduced in paralyzed embryos, $1.39 \pm 0.07 \mu \mathrm{m}(n=484)$ in embryos paralyzed during E16 to E21 as compared to $1.61 \pm 0.06 \mu \mathrm{m}(n=270)$ in controls. This $25 \%$ reduction in mean cross-sectional area was significant at the level $0.02<p<0.05$.

\section{Number of synaptic inputs}

As described under "Materials and Methods," the use of curare to prevent muscle contraction was unsatisfactory due to its powerful depolarizing action. Paralyzed muscle fibrillated vigorously, until depolarized by dTC. E21 control muscles did not fibrillate. Many experimental muscles were discarded because the concentration of dTC required to completely block contraction caused too great a diminution of epps in surface muscle fibers.

The lowest threshold response seen in most units in paralyzed muscles had a small amplitude and slow rate of rise. This was assumed to be due to electrical coupling between muscle fibers (Dennis et al., 1981) and was not counted. Following depolarization with dTC it was difficult to demonstrate electrical coupling between paralyzed muscle fibers (an action potential evoked in one fiber gave rise to a depolarization of $1 \mathrm{mV}$ or less in an immediately adjacent fiber), and we found no evidence to suggest that fast-rising increments in the epp were generated in units other than the one impaled.

Data for the number of synaptic inputs per physiologically defined muscle unit were taken from experiments on six diaphragms from embryos paralyzed during E17 to E21, and five diaphragms from E21 control embryos (Table II). There were on average 2.66 inputs to control units, and 5.54 to paralyzed units. Diaphragms from E21 control embryos contain 8,484 muscle units, and embryos paralyzed during E17 to E21 contain 4,986 units (Harris, 1981a). Thus there were totals of 22,567 synaptic inputs to fibers in control muscles, and 27,622 in paralyzed muscles, a $22 \%$ excess. 


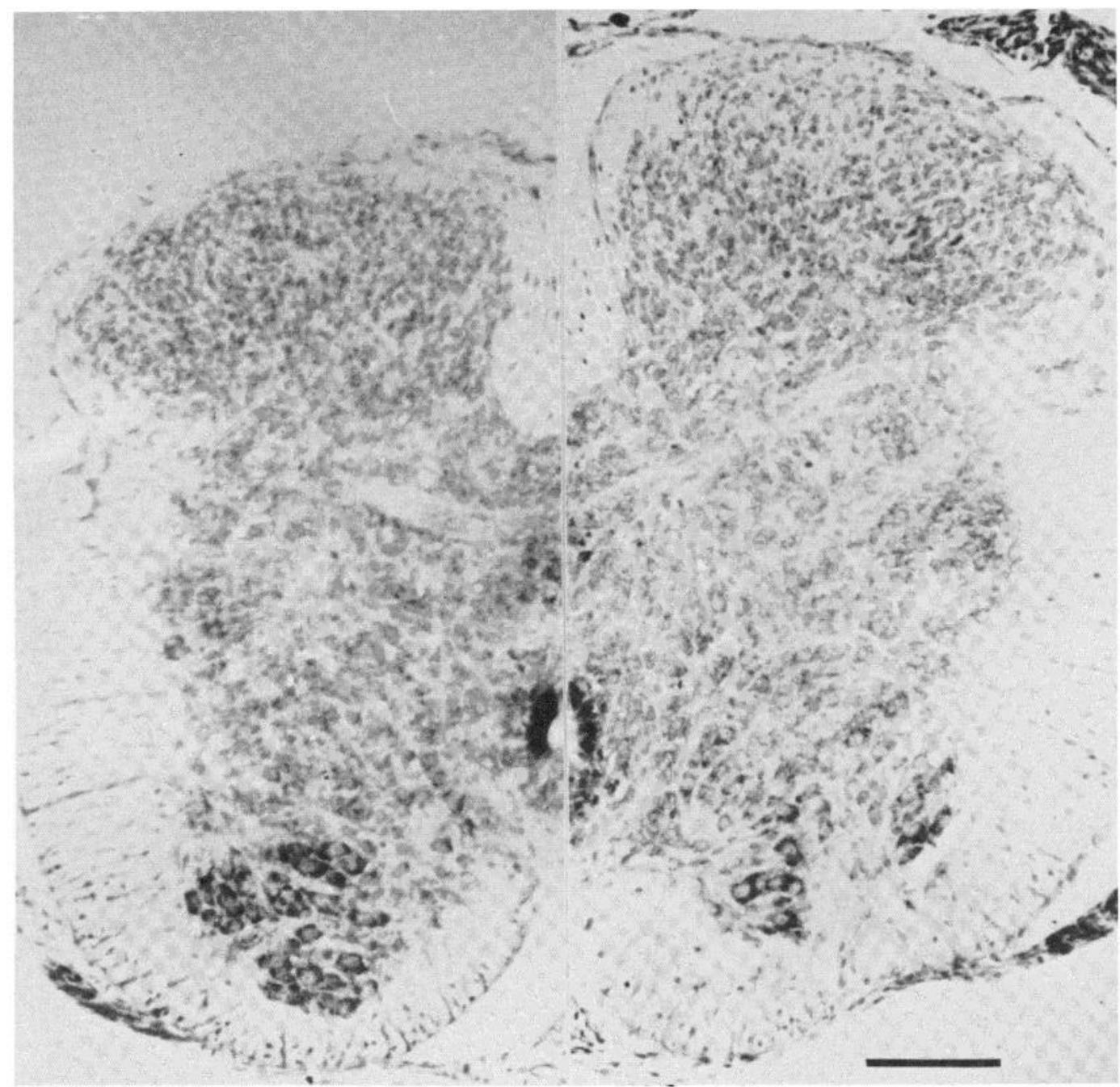

Figure 2. Cross-sections of upper thoracic spinal cords from E21 control and E16 to E21 paralyzed embryos, Nissl stain. Left, Paralyzed cord; note the compact cluster of ventral horn cells with dense Nissl substance. Right, Control cord; scattered ventral horn cells of variable size. Sections were chosen to illustrate these points, and are not from identical levels of cord. Scale bar, $100 \mu \mathrm{m}$.

\section{Average motor unit size}

Ventral root axons from embryos paralyzed during E17 to E21 were $124 \%$ of the number in E21 controls (Fig. 1). Thoracic cord motoneuron cell bodies and phrenic nerve axons were counted in embryos paralyzed during E16 to E21, and figures for paralysis beginning on E17 were obtained by interpolation (justified by the shape of the curve for ventral root axons). These interpolations predict that motoneuron cell bodies were $124 \%$ of the control number, and phrenic nerve axons were $145 \%$ of the number in E21 controls. From these figures it is possible to calculate the ratio of synaptic inputs contributed per motoneuron (i.e., average motor unit size) for paralyzed and control embryos. The results from ventral root axon and motoneuron cell body counts both give $99 \%$, and those from phrenic nerves (in which we could not distinguish between motor and sensory axons) give
$84 \%$. These results suggest that, through a process of increased redundancy of innervation, motoneurons in paralyzed animals establish motor units of the same size as in control embryos, even though the absolute number of motoneurons is greater than normal, and the number of synaptic sites is reduced.

\section{Discussion}

A quantitative study of the development of nervemuscle junctions must take into account the number of motoneurons, the number of muscle fibers, and the number of motor nerve inputs to each muscle fiber. This has recently been done by Bourgeois and Toutant (1982) for the embryonic chick PLD muscle, and we now add an account in a mammal. Numbers of synaptic inputs and of muscle fibers during embryonic development of rat internal intercostal and diaphragm muscles, respectively, 
TABLE I

Motoneuron cell bodies in thoracic spinal cord (T1 to T6 inclusive)

\begin{tabular}{|c|c|c|c|}
\hline \multicolumn{2}{|c|}{ Controls (E21) } & \multicolumn{2}{|c|}{ TTX (E16-E21) } \\
\hline \multicolumn{2}{|l|}{6,699} & \multicolumn{2}{|l|}{7,763} \\
\hline \multicolumn{2}{|l|}{7,511} & \multicolumn{2}{|l|}{8,762} \\
\hline 7,297 & & \multicolumn{2}{|l|}{9,323} \\
\hline \multirow{2}{*}{\multicolumn{2}{|c|}{6,248}} & & \\
\hline & & \multicolumn{2}{|l|}{7,769} \\
\hline \multirow{2}{*}{\multicolumn{2}{|c|}{$6,939 \pm 575$}} & \multirow{2}{*}{\multicolumn{2}{|c|}{$\begin{array}{c}9,041 \pm 1572 \\
0.025<p<0.05\end{array}$}} \\
\hline & & & \\
\hline \multicolumn{4}{|c|}{ Phrenic nerve: Premyelinated axons } \\
\hline Controls (E21) & \multicolumn{2}{|c|}{ Paralyzed (TTX E15-E21) } & TTX E16-E21 \\
\hline 278 & \multicolumn{2}{|l|}{793} & 603 \\
\hline 403 & \multicolumn{2}{|l|}{841} & 613 \\
\hline 362 & \multicolumn{2}{|l|}{735} & 469 \\
\hline 397 & & 632 \\
\hline 240 & & & 554 \\
\hline \multicolumn{4}{|l|}{453} \\
\hline \multicolumn{4}{|l|}{430} \\
\hline$\overline{366} \pm 79$ & \multirow{2}{*}{\multicolumn{2}{|c|}{$\begin{array}{l}\overline{790} \pm 53 \\
p<0.000025\end{array}$}} & $\overline{574} \pm 65$ \\
\hline & & & $p<0.0005$ \\
\hline \multicolumn{4}{|c|}{ Phrenic nerve: Axons grouped in bundles } \\
\hline \multicolumn{2}{|c|}{ Controls } & \multicolumn{2}{|c|}{ Paralyzed } \\
\hline E15 (all axons) & E21 & TTX E15-E21 & TTX E16-E21 \\
\hline Prox. Dist. & Prox. Dist. & Prox. Dist. & Prox. Dist. \\
\hline $1,270-1,026$ & $1,628-580$ & $1,730-1,089$ & $1,612-787$ \\
\hline \multirow[t]{2}{*}{$1,079-1,211$} & $1,850-913$ & 1,895-lost & $1,648-1,007$ \\
\hline & & $1,237-977$ & \\
\hline
\end{tabular}

have been determined (Dennis et al., 1981; Harris, 1981a, b), and the present work extends these studies by taking into account the number of motoneurons. It is now possible to calculate the mean number of nerve-muscle contacts per motoneuron during the full course of muscle development (Table III, Fig. 6). We also investigate the mechanisms of nerve-muscle interaction by studying the consequences of perturbing the numbers of nerve and muscle fibers.

Accuracy of data. Counts of motoneurons supplying motor axons to the diaphragm muscle are all indirect. Although absolute numbers are not critical to our argument, the relative numbers in paralyzed and control animals are important. We did not attempt to count motoneuron cell bodies supplying the phrenic nerve, as there is an almost 3-fold range of ventral root axon numbers between $\mathrm{C} 4$ and $\mathrm{C} 6$ in the adult rat (Coggeshall et al., 1977), so that small differences in the definition of segmental boundaries would introduce large errors. We counted cell bodies in segments $\mathrm{T} 1$ to $\mathrm{T} 6$ inclusive, where ventral roots are fairly uniform in size and where there was sufficient length of cord to ensure that small differences in the definition of segmental borders would not affect the accuracy.

The use of ventral root axons to determine motoneuron numbers is subject to the uncertainty that an appar- ent loss of neurons might be due to loss of axon branches, as seen in the early stages of development of chick motoneurons by Chu-Wang and Oppenheim (1978). In confirmation of Fraher (1974), we saw no differences between counts from either end of ventral roots, but it is possible that branching occurred within the spinal cord. Lance-Jones (1982) counted horseradish peroxidase (HRP)-labeled motoneurons in mice, finding that $85 \%$ of motoneuron death occurred during E13 to E15. In our study, $80 \%$ of axon loss occurred during E15 to E16. The general similarity of these results indicates that axon loss was substantially due to motoneuron death, with retraction of branches possibly playing a subsidiary role during E15. In E21 embryos the ratio of axon numbers, paralyzed versus control, was very similar to that derived from thoracic motoneuron cell body counts, so that these different measures are consistent with one another and show that from E16 onward there was a 1:1 relationship between axon loss and motoneuron death.

Muscle fiber counts come from earlier work by Harris (1981a). Improvements in our technique for paralysis mean that recently derived data for motoneuron numbers in embryos paralyzed from E16 might not correlate well with muscle fiber numbers derived from the earlier study. For this reason, we chose to estimate numbers of synaptic inputs per muscle fiber in E17 animals so that we could confidently employ the earlier data for muscle fiber members.

Numbers of synaptic inputs per muscle fiber were determined electrophysiologically. Values from control animals were the same as those recorded by others (Bennett and Pettigrew, 1974). Values from experimental animals were internally consistent (Table II), and the counting technique was in principle more accurate than in controls. However, the preparations were close to the limits of utility because of depolarization by the large doses of dTC required to stop twitching. Well over half the preparations we examined were discarded because surface fibers were too depolarized, and if the dose of dTC was reduced, the preparation twitched. We noted in other preparations that if a penetration did not initially meet our criterion for resting potential but then improved, we could often detect a greater number of increments in the epp. We do not think it likely that there was a consistent underestimate of the number of increments in impalements that did meet our criteria. We made extensive histological studies in an attempt to obtain an independent estimate of preterminal axon numbers, but did not succeed. Two problems were that we could not randomly sample endplates but had to select junctions favorably located on muscle fibers, and there were so many preterminal axons, unmyelinated and often in fascicles, that it was not often possible to make accurate counts. We did not attempt to repeat Srihara and Vrbova's (1980) electron microscope counts of nerve

Figure 3. A, Detail of phrenic nerve from rat embryo paralyzed during E15 to E21 showing premyelinated axons, Schwann cell nuclei, and axons grouped in a Remak bundle. Specialized membrane contracts are seen within some mesaxons. $B$, Selected areas of $\mathrm{C} 5$ ventral roots from rat embryos. $i$, E21 control; $i i$, paralyzed E15 to E21, at the same magnifications. Note differences in the numbers of axons and Schwann cell nuclei, and in axon diameter. Paralyzed roots invariably had a greater cross-sectional area and a larger number of axons per unit area than did controls. Scale bars, $1 \mu \mathrm{m}$. 

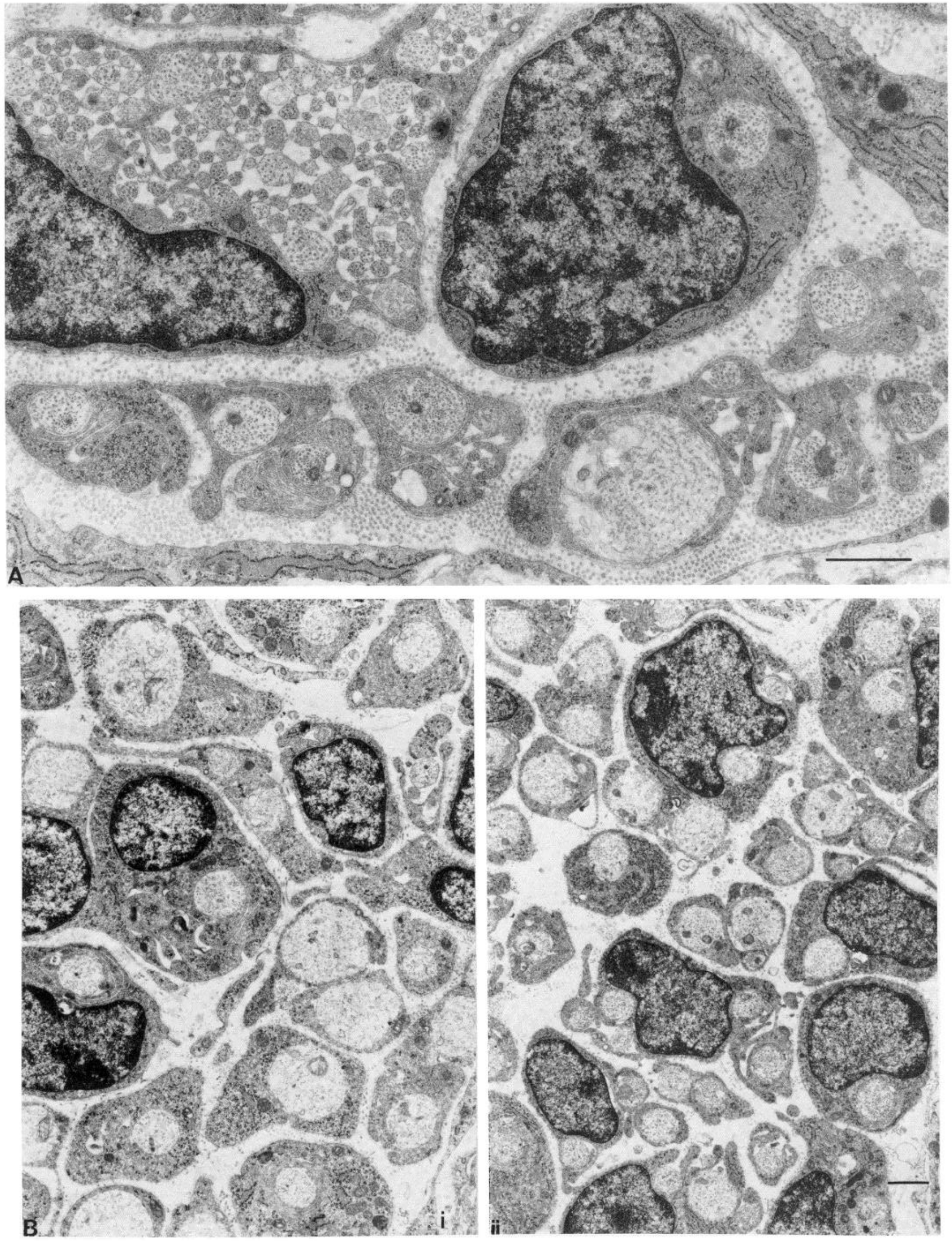


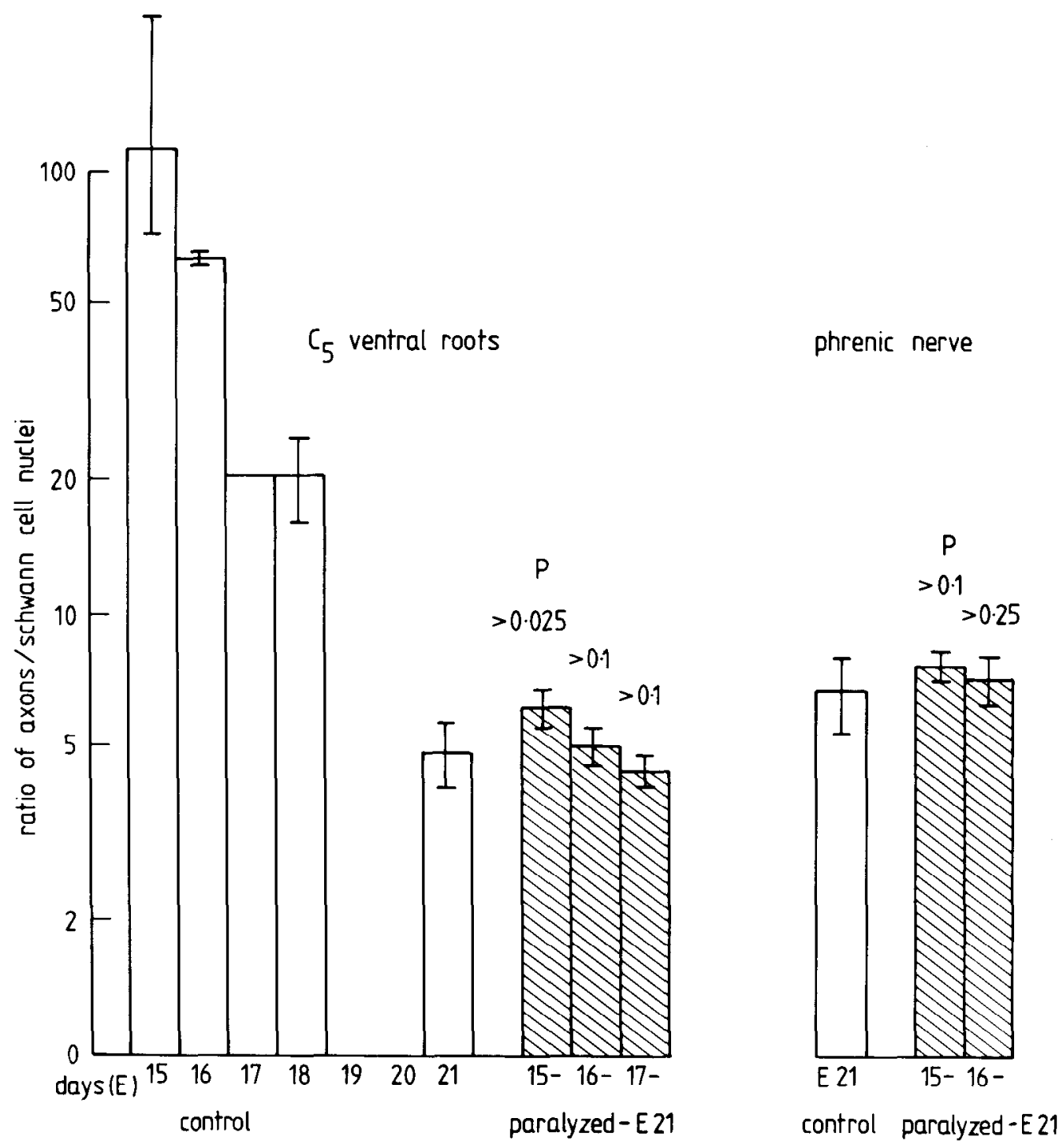

Figure 4. Histogram of the ratio of axons to Schwann cell nuclei in sections of C5 ventral root and phrenic nerve from control and paralyzed embryos. There is a progressive increase in Schwann cell numbers as ventral roots develop, and this is not affected by paralysis from E16 or E17. A statistical test of significance indicates a slight effect of paralysis from E15, but this reflects a difference of less than a day in progress of ventral root development. There is no significant difference between paralyzed and control phrenic nerves.

terminal profiles in endplates, as it is not possible with this technique to relate the number of profiles to the number of preterminal axons.

Motoneuron death. Neuronal death is now accepted as commonplace during development of the nervous system (Cowan, 1973). Motoneuron death has been best studied in the chick, as for technical reasons histological definition of motoneurons is more difficult in mammals. Studies of the time course of motoneuron death in mice include those by Romanes (1946) and Flanagan (1969); the best data currently available are those of LanceJones (1982). She defined motoneurons by uptake of HRP injected into hindlimb muscles, and found (in the mouse) that the rate of motoneuron loss peaked between E13 and E14, and cell numbers became stable after E18. Reports of motoneuron death at later times (see Rootman et al., 1981, for references) may be criticized on technical grounds. The histogram of time course and magnitude of motoneuron loss presented by Lance-Jones (1982) is similar to our curve of ventral root axon loss in rats, displaced 2 days earlier.

Paralysis from E15 or E16 until E21 did not affect the number of axons in C5 dorsal roots. We could not distinguish premyelinated axons much earlier than E21, in contrast to $\mathrm{C} 5$ ventral root axons which can all be assumed to be premyelinated (Coggeshall et al., 1977). If paralysis affected the survival of a single class of dorsal root axons, for example, large muscle afferents, this small change in number of $\mathrm{C} 5$ dorsal root axons might not have been seen. This may explain the greater degree of survival of axons in paralyzed phrenic nerves as compared to $\mathrm{C} 5$ ventral roots.

There is an inverse relation between cell death and nerve terminal formation. As illustrated in Figure 6, 
motoneuron death is complete at the same time that the maximum number of nerve terminals per motoneuron has been achieved. A simple hypothesis to explain normal death and the effects of paralysis is that, in order to survive, motoneurons require a trophic substance released by muscle cells. The amount a motoneuron can take up depends upon the number of nerve terminals it possesses. Muscle contractile activity inhibits release of this factor, and in paralyzed muscles it is released in excess. As motoneurons develop, the first to form terminals (and at any given time those with more terminals) have a selective advantage. Electrical stimulation of muscle should inhibit survival of motoneurons by cutting off

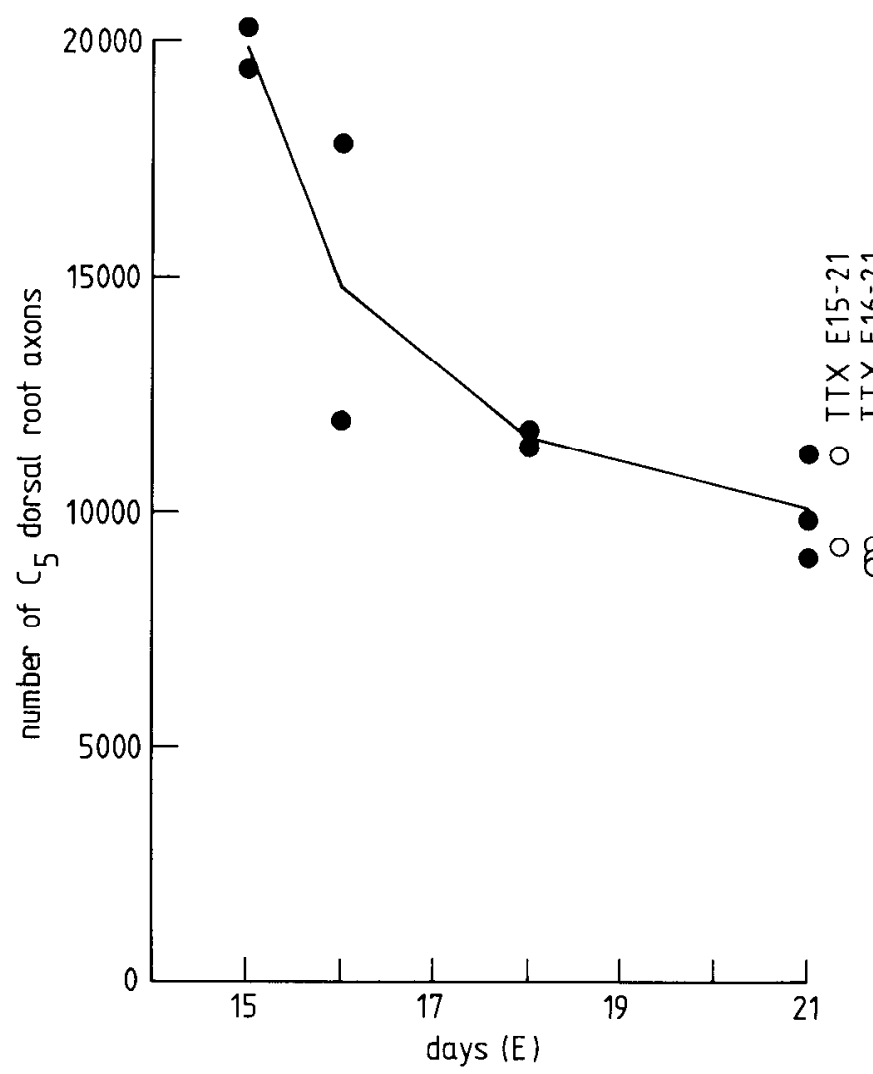

Figure 5. Numbers of C5 dorsal root axons in rat embryos aged E15 to E21 (solid circles) and number of axons in E21 embryos after paralysis during the intervals listed (open circles). release of the factor. Oppenheim and Nunez (1982) showed that electrical stimulation of chick motoneurons increases the degree of death. According to our hypothesis, their results are due to indirect stimulation of muscle, rather than to a direct effect of electrical activity on neurons.

Effect of paralysis. Paralysis in ovo has been shown to rescue embryonic avian motoneurons from cell death (Laing and Prestige, 1978; Pittman and Oppenheim, 1978; Creazzo and Sohal, 1979). Furthermore, Srihari and Vrbova (1980), using electron microscopy, saw an increase in the number of terminals. These experiments are here confirmed in a mammalian embryo.

Our procedure, when applied to E15 embryos, rescued $26 \%$ of the motoneurons normally destined to die; applied to E16 embryos it rescued 45\%; and applied to E17 embryos it rescued $48 \%$. This may reflect the different rates of cell death at these different times. Using the data in Figure 1, it can be calculated that cells surviving until E21, after paralysis beginning on E15, represent all those present $22 \mathrm{hr}$ afer paralysis was initiated; those on

TABLE II

Number of synaptic inputs to rat diaphragm muscle fibers

The number of synaptic inputs to a fiber was estimated by counting increments in epp amplitude as the intensity of nerve stimulation was varied. Each figure is the mean value from one muscle.

\begin{tabular}{|c|c|c|c|}
\hline \multicolumn{2}{|l|}{ Controls, E21 } & \multicolumn{2}{|c|}{ TTX-paralysis E17-E21 } \\
\hline \multicolumn{2}{|r|}{$n^{a}$} & & $n$ \\
\hline 1.73 & 22 & 5.64 & 18 \\
\hline 2.31 & 36 & 5.00 & 6 \\
\hline 5.00 & 5 & 6.36 & 14 \\
\hline 2.83 & 40 & 4.38 & 8 \\
\hline \multirow[t]{2}{*}{3.13} & \multirow[t]{2}{*}{30} & 5.50 & 4 \\
\hline & & 5.43 & 7 \\
\hline$\overline{2.66}$ & $\overline{133}$ & $\overline{5.54}$ & $\overline{57}$ \\
\hline \multicolumn{4}{|c|}{ Number of synaptic inputs from each motoneuron } \\
\hline & Controls, E21 & $\mathrm{TT}$ & E17-E21 \\
\hline Inputs/fiber & 2.66 & & \\
\hline Muscle units & 8,484 & & \\
\hline Terminals/nuscle & 22,567 & & \\
\hline Motoneurons $^{b}$ & 280 & & \\
\hline Inputs/motoneuron & 81 & & \\
\hline
\end{tabular}

${ }^{a} n$, number of fibers.

${ }^{b}$ Control data from Lubinska and Waryszewska, (1974); data for paralyzed motoneurons scaled from counts of $\mathrm{C} 5$ ventral root axons.

TABLE III

Number of terminals per motoneuron during embryonic development

Data for numbers of inputs per unit are from internal intercostal muscles, as noted below. If values from E21 diaphragm muscles were scaled to match intercostals, then TTX-paralyzed motoneurons would have 66 terminals at E21; the actual value for diaphragm is 80 (Table II).

\begin{tabular}{|c|c|c|c|c|c|c|c|c|}
\hline & E15 & E16 & E17 & E18 & E19 & E20 & $\mathrm{E} 21$ & Adult \\
\hline Muscle units (Harris, 1981a) & $900^{a}$ & 1,526 & 2,320 & 4,845 & 6,643 & 7,731 & 8,484 & 11,918 \\
\hline Inputs/unit $^{b}$ (Dennis et al., 1981) & 1.85 & 2.83 & 3.06 & 3.04 & 3.25 & 2.70 & 2.20 & 1.00 \\
\hline Phrenic motoneuron numbers ${ }^{c}$ & 1,660 & 564 & 419 & 351 & $327^{\alpha}$ & $304^{a}$ & 280 & 280 \\
\hline Terminals/muscle & 1,665 & 4,319 & 7,099 & 14,729 & 21,590 & 20,874 & 18,665 & 11,918 \\
\hline Terminals/motoneuron & 1 & 7.6 & 16.9 & 42 & 66 & 69 & 67 & 43 \\
\hline
\end{tabular}

${ }^{a}$ Data by extrapolation or interpolation.

${ }^{\circ}$ Data from internal intercostal muscles; assumed to be a constant proportion of numbers from diaphragm, which are 2.66 on E21 compared to 2.2 for intercostals.

"Number of phrenic motoneurons scaled from C5 ventral root axon numbers; adult number of phrenic motoneurons from Lubinska and Waryszewska (1974). 


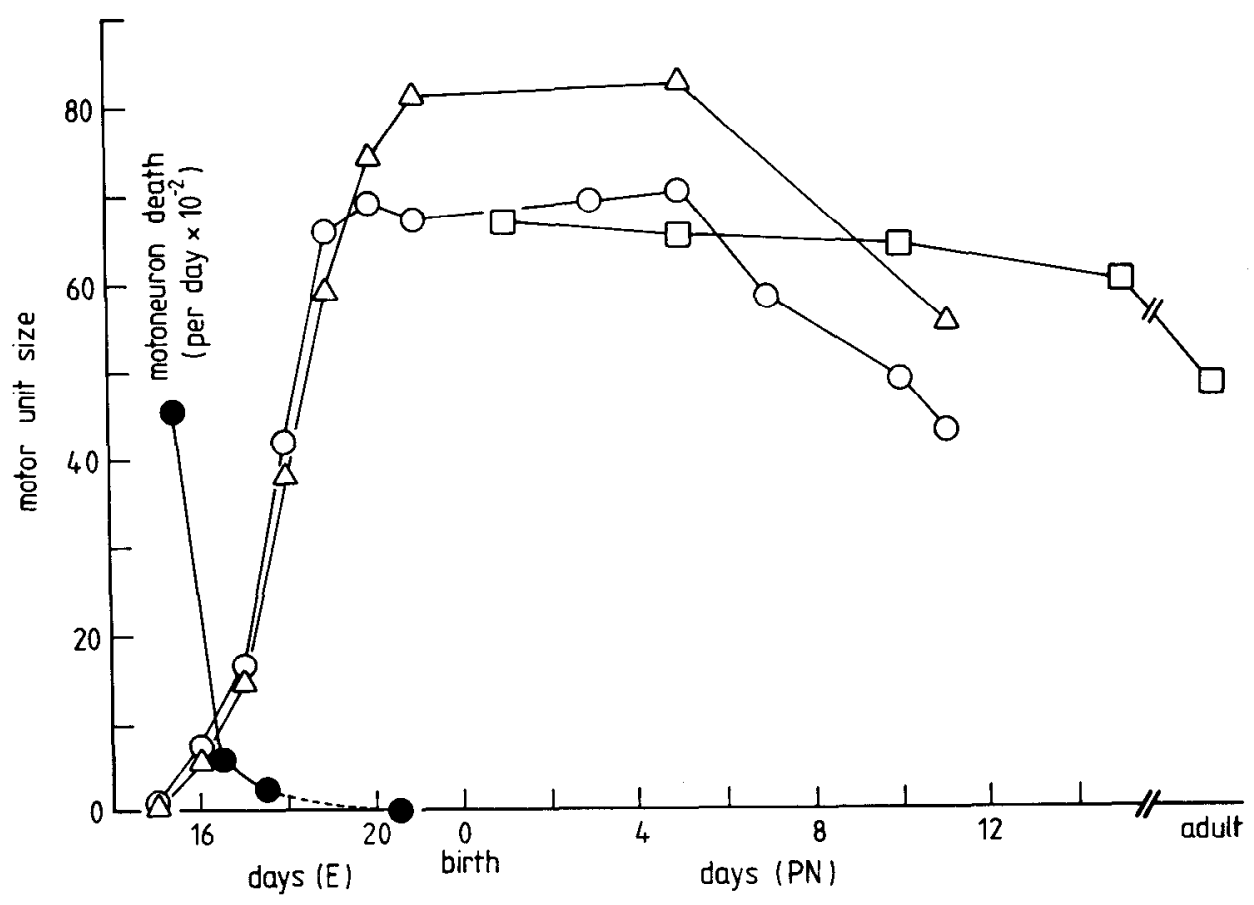

Figure 6. Number of synaptic terminals per motoneuron in developing rat embryos. $O$, data from Dennis et al. (1981) and Harris (1981a) (intercostal and diaphragm muscles); $\triangle$, data from Bennett and Pettigrew (1974), the present study (E21), and Harris (1981a) (diaphragm muscles); $\square$, data from Betz et al. (1979) (lumbrical muscles, scaled to match intercostal data at E21); , number of $\mathrm{C} 5$ ventral root axons dying per day.

E16 represent cells present $25 \mathrm{hr}$ later; and those on E17 represent cells present $25 \mathrm{hr}$ later. In other words, cells may be committed to die one day in advance, and paralysis rescues all cells not so committed. The 24-hr lag would in part represent a period of irreversible commitment to cell death and, in part, the time required for stimulation of secretion of the motoneuron trophic factor hypothesized above, and its retrograde axonal transport.

This gives rise to the interesting possibility that motoneurons dying during E15 were committed to die during E14, at a very early stage in muscle development, before any structural features of endplates can be recognized. McLennan (1982) suggested that there is a 1:1 relation between the number of primary myotubes in chick muscles at the time of determination of motoneuron death and the number of motoneurons in the adult. Although we have not counted the number of myotubes in E14 rat muscles, numbers extrapolated from data in Harris (1981a) are not inconsistent with McLennan's (1982) speculation. Certainly, determination of cell death for the majority of motoneurons destined to die in our study occurred before any endplate structures or postsynaptic receptor aggegations can be recognized (Bevan and Steinbach, 1977; Harris, 1981b).

The mean number of functioning nerve-muscle contacts per paralyzed motoneuron was the same as in controls. This indicates that motoneurons normally destined to die are capable of forming functional synapses, and they constitute a normal subset of the motoneuron population. We cannot, however, exclude the unlikely possibility that motoneurons normally destined to survive sprouted and formed an excess number of terminals, whereas motoneurons normally destined to die extended axons along the full length of the phrenic nerve but formed few or no functional terminals.

Schwann cells. Paralysis had little effect on the ratio of axons to Schwann cell nuclei in cross-sections of C5 ventral roots or phrenic nerves (Fig. 4). This result indicates that the number of Schwann cells in a developing nerve reflects the physical presence of axons, and not their history of electrical activation. This conclusion is not consistent with that of Toutant et al. (1981) who suggested that electrical stimulation increased the number of Schwann cells in embryonic chick nerves. Our result also gives evidence for promyelin formation about axons normally destined to die, as seen already by Crcazzo and Sohal (1979) in duck embryos.

Motor unit size during development. Numbers of muscle fibers contacted per motoneuron are referred to the diaphragm muscle, based on Lubinska and Waryszewska's (1974) observation that the adult rat hemidiaphragm receives 280 motor axons. It is assumed that the number of motor axons in the phrenic nerve bears a fixed relation to the number of C5 ventral root axons. The numbers of nerve terminals per motoneuron listed in Table III are derived using data for the number of synaptic inputs per muscle unit from internal intercostal muscles (Dennis et al., 1981). The average motor unit size steadily increases until E19 and then remains constant until postnatal day 5 (PN5). A limited amount of data for numbers of synaptic inputs to rat diaphragm muscle fibers determined by Bennett and Pettigrew (1974) gives a very similar curve (Fig. 6) with the size of motor units remaining constant from E21 until PN5 or later. Betz et al. (1979), 
in rat lumbrical muscles, found that motor unit size remains constant during the first 10 postnatal days and then declines to the adult value as polyneuronal innervation of muscle fibers is withdrawn. Their data (scaled to match intercostal and diaphragm muscle values on E21) are illustrated in Figure 6. Similarly, in the chick PLD muscle (Bourgeois and Toutant, 1982), motor unit size remains constant from E16 to at least 6 weeks postnatal, despite a more than 2 -fold increase in number of muscle fibers.

From the time when this stable number of nervemuscle contacts has first formed, until the time terminals retract to the adult number of one per muscle fiber, the number of muscle units approximately doubles (Harris,1981a). Accordingly, nerve-muscle contacts must continually be reorganized within the muscle during this period. Each muscle unit consists of a primary myotube and associated secondary myotubes within a single basal lamina (Kelly and Zacks, 1969; Ontell and Dunn, 1978; Harris, 1981a, b). Secondary myotubes cannot develop without innervation (Harris, 1981a; McLennan, 1983), and it is likely that, as each secondary myotube separates from its primary myotube, some nerve terminals are transferred with it. Betz et al. (1980) showed in partially denervated neonatal muscles that denervated units are not reinnervated, but new muscle fibers continue to form and to become innervated, as would be expected in this model.

Even when, as a result of chronic paralysis, the number of motoneurons was increased and the number of muscle units decreased, each motoneuron contacted its normal number of muscle cells. Competition between nerve terminals, if it occurred at this stage, should be inhibited by paralysis (Thompson et al., 1979). The fact that the average motor unit size was unchanged in paralyzed muscles makes it unlikely that competition between terminals is important in determining embryonic motor unit size, and we suggest that some mechanism intrinsic to motoneurons determines the number of nerve-muscle contacts they should form. In contrast, the effect of paralysis on motoneuron death indicates that competition (presumably for uptake of a muscle-released factor) is normally important in determining the number of motor units. Also, the postnatal reduction in the mean number of terminals per motoneuron is well explained by a process of competition between terminals (Thompson et al., 1979; Betz et al., 1980).

Regeneration of nerve terminals. One implication of our conclusions is that once an embryonic motoneuron has achieved its maximum number of terminals, it should be unable to form more, at least until it has reached its adult state of differentiation (Pollock and Harris, 1981). Dennis and Harris (1980) found that rat intercostal motoneurons, axotomized at any time after birth, could not re-establish functional nerve terminals until the rats were at least 3 weeks of age, although they could quickly regenerate axons. In contrast, these motoneurons can regenerate a limited number of terminals if axotomized in utero before their full number of terminals has been formed (Sheard, 1981; Sheard et al., 1984).

Regulalion of muscle fiber numbers. The number of fibers in an adult muscle is determined genetically (Luff and Goldspink, 1970; Hooper, 1978); the mechanism of determination is unknown. Innervation is an absolute prerequisite for development of the normal number of fibers (Betz et al., 1980; Harris, 1981a). We can now ask whether regulation of nerve terminal numbers is sufficient to explain genetic determination of muscle size. The fact that mean motor unit size is not the same in different adult muscles (Bixby et al., 1980) excludes any simple hypothesis of this kind.

Why limit motor unit size? Our major conclusion is that embryonic motoneurons are determined to contact a set number of muscle fibers in their appropriate muscle. This reaffirms and extends the conclusion of Brown et al. (1976) that there is an intrinsic upper limit to embryonic motor unit size. We suggest that competition for uptake of a muscle-released growth factor determines the number of motor units, but that it is not necessary to postulate the existence of competition between terminals in order to explain determination of embryonic motor unit size. Brown et al. (1976) present evidence that the late reduction in motor unit size that occurs at about 2 weeks postnatal in rat soleus muscles may also, in part, depend on intrinsic mechanisms as well as competition between terminals (Betz et al., 1980).

We assume that this property of embryonic motoneurons has a role in determining the precise and consistent patterning of size and of innervation of any given muscle in an adult animal. A "thought experiment" to describe this role is to imagine what would happen if there was no limit to the number of muscle fibers a motoneuron could contact, and nerve terminal numbers were regulated solely by competition between themselves. This would result in a process of positive feedback in which the first motoneurons to innervate a muscle would be at an advantage in taking up muscle-released motoneuron growth factor(s) and hence in forming still more terminals. Motoneurons with fewer terminals would die. Muscles would eventually contain a few very large motor units, regardless of their role in the animal.

\section{References}

Bennett, M. R., and A. G. Pettigrew (1974) The formation of synapses in striated muscle during development. J. Physiol. (Lond.) 241: 515-545.

Betz, W. J., J. H. Caldwell, and R. R. Ribchester (1979) The size of motor units during postnatal development of rat lumbrical muscle. J. Physiol. (Lond.) 297: 463-478.

Betz, W. J., J. H. Caldwell, and R. R. Ribchester (1980) The effects of partial denervation at birth on the development of muscle fibres and motor units in rat lumbrical muscle. J. Physiol. (Lond.) 303: 265-279.

Bevan, S., and J. H. Steinbach (1977) The distribution of alphabungarotoxin binding sites on mammalian skeletal muscle developing in vivo. J. Physiol. (Lond.) 267: 195-213.

Bixby, J. L., J. H. R. Maunsell, and D. C. Van Essen (1980) Effects of motor unit size on innervation patterns in neonatal mammals. Exp. Neurol. 70: 516-524.

Bourgeois, J. -P., and M. Toutant (1982) Innervation of avian latissimus dorsi muscles and axonal outgrowth pattern in the posterior latissimus dorsi motor nerve during embryonic development. J. Comp. Neurol. 208: 1-15.

Brown, M. C., J. K. S. Jansen, and D. Van Essen (1976) Polyneuronal innervation of skeletal muscle in new-born rats 
and its elimination during maturation. J. Physiol. (Lond.) 261: 387-422.

Chu-Wang, I. -W., and R. W. Oppenheim (1978) Cell death of motoneurons in the chick embryo spinal cord. II. A quantitative and qualitative analysis of degeneration in the ventral root, including evidence for axon outgrowth and limb innervation prior to cell death. J. Comp. Neurol. 177: 59-86.

Coggeshall, R. E., D. G. Emery, H. Ito, and C. W. Maynard (1977) Unmyelinated and small myclinated axons in rat ventral roots. J. Comp. Neurol. 173: 175-184.

Cowan, W. M. (1973) Neuronal death as a regulative mechanism in the control of cell number in the nervous system. In Development and Aging in the Nervous System, M. Rockstein, ed., pp. 19-41, Academic Press, Inc., New York.

Creazzo, T. L., and G. S. Sohal (1979) Effects of chronic injections of $\alpha$-bungarotoxin on embryonic cell death. Exp. Neurol. 66: 135-145.

Dennis, M. J., and A. J. Harris (1980) Transient inability of neonatal rat motoneurons to reinnervate muscle. Dev. Biol. 74: $173-183$.

Dennis, M. J., L. Ziskind-Conhaim, and A. J. Harris (1981) Development of neuromuscular junctions in rat embryos. Dev. Biol. 81: 266-279.

Flanagan, A. E. H. (1969) Differentiation and degeneration in the motor column of foetal mouse. J. Morphol. 129: 281-305.

Fraher, J. P. (1974) A numerical study of cervical and thoracic ventral nerve roots. J. Anat. 118: 127-142.

Harris, A. J. (1981a) Embryonic growth and innervation of rat skeletal muscles. I. Neural regulation of muscle fibre numbers. Philos. Trans. R. Soc. Lond. (Biol.) 293: 257-277.

Harris, A. J. (1981b) Embryonic growth and innervation of rat skeletal muscles. III. Neural regulation of junctional and extrajunctional acetylcholine receptor clusters. Philos. Trans. R. Soc. Lond. (Biol.) 293: 287-314.

Harris, A. J., and C. D. McCaig (1983) Embryonic proliferation of autonomic axons following muscle denervation. Neurosci. Lett. 11: S47.

Hooper, A. C. B. (1978) Muscles and bones of large and small mice compared at equal body weights. J. Anat. 127: 117-123.

Hubel, D. H., and T. N. Wiesel (1970) The period of susceptibility to the physiological effects of unilateral eye closure in kittens. J. Physiol. (Lond.) 206: 419-436.

Kelly, A. M., and S. I. Zacks (1969) The histogenesis of rat intercostal muscle. J. Cell Biol. 42: 135-153.

Laing, N. G., and M. C. Prestige (1978) Prevention of spontaneous motoneurone death in chick embryos. J. Physiol. (Lond.) 282: 33-34P.

Lamb, A. H. (1981) Target dependency of developing motoneurons in Xenopus laevis. J. Comp. Neurol. 203: 157-171.

Lance-Jones, C. (1982) Motoneuron cell death in the developing lumbar spinal cord of the mouse. Dev. Brain Res. 4: 473-479.

Lance-Jones, C., and L. Landmesser (1981) Pathway selection by chick lumbosacral motoneurons during normal development. Proc. R. Soc. Lond. Biol. 214: 1-18.

Lubinska, L., and J. Waryszewska (1974) Fibre population of the phrenic nerve of rat: Changes of myelinated fibre dimensions along the nerve and characteristics of axonal branchings. Acta Neurobiol. Exp. (Warsz.) 34: 525-541.
Luff, A. R., and G. Goldspink (1970) Total number of fibres in mucles of several strains of mice. J. Anim. Sci. 30: 891-893.

McLennan, I. S. (1982) Size of motoneuron pool may be related to number of myotubes in developing muscle. Dev. Biol. 92: 263-265.

McLennan, I. S. (1983) Neural dependence and independence of myotube production in chicken hindlimb muscles. Dev. Biol. 98: 287-294.

Mills, R. G., and J. J. Bray (1979) A slow-release technique for inducing prolonged paralysis by tetrodotoxin. Pflugers Arch. 383: $67-70$.

Ontell, M., and R. F. Dunn (1978) Neonatal muscle growth: A quantitative study. Am. J. Anat. 152: 539-556.

Oppenheim, R. W., and R. Nunez (1982) Electrical stimulation of hindlimb increases neuronal cell death in chick embryo. Nature 295: 57-59.

Oppenheim, R. W., I.-W. Chu-Wang, and J. L. Maderdrut (1978) Cell death of motoneurons in the chick embryo spinal cord. III. The differentiation of motoneurons prior to their induced degeneration following limb-bud removal J. Comp. Neurol. 177: 87-112.

Pittman, R., and R. W. Oppenheim (1978) Neuromuscular blockade increases motoneurone survival during normal cell death in the chick embryo. Nature 271: 364-366.

Pollock, M., and A. J. Harris (1981) Accuracy in peripheral nerve regeneration. Trends Neurosci. 4: 18-20.

Redfern, P. A. (1970) Neuromuscular transmission in newborn rats. J. Physiol. (Lond.) 270: 299-310.

Romanes, G. J. (1946) Motor localization and the effects of nerve injury on the ventral horn cells of the spinal cord. J. Anat. 80: 117-131.

Rootman, D. S., W. G. Tatton, and M. Hay (1981) Postnatal histogenetic death of rat forelimb motoneurons. J. Comp. Neurol. 199: 17-27.

Sheard, P. (1981) The reinnervation of embryonic and neonatal skeletal muscle. Dip. Sci. thesis, University of Otago, Dunedin, New Zealand.

Sheard, P., C. D. McCaig, and A. J. Harris (1984) Critical periods in rat motoneuron development. Dev. Biol., in press.

Srihari, T., and G. Vrbova (1980) Effects of neuromuscular blocking agents on the differentiation of nerve-muscle connections in slow and fast chick muscles. Dev. Growth Differ. 22: $645-657$.

Stent, G. S. (1981) Strength and weakness of the genetic approach to the development of the nervous system. In Studies in Developmental Neurobiology, W. M. Cowan, ed., pp. 288-321, Oxford University Press, New York.

Thompson, W., D. P. Kuffler, and J. K. S. Jansen (1979) The effect of prolonged, reversible block of nerve impulses on the elimination of polyneuronal innervation of new-born rat skeletal muscle fibres. Neuroscience 4: 271-281.

Toutant, M., J. P. Toutant, D. Renaud, and G. Le Douarin (1981) Effects of spinal cord stimulation on the differentiation of posterior latissimus dorsi nerve in the chick embryo. Exp. Neurol. 72: 267-280.

Ziskind, L., and M. J. Dennis (1978) Depolarising effect of curare on cmbryonic rat muscles. Nature 276: 622-623. 